\title{
A novel testis-specific gene, SPAG4, whose product interacts specifically with outer dense fiber protein ODF27, maps to human chromosome 20q11.2
}

\author{
H. Tarnasky, ${ }^{a}$ D. Gill, ${ }^{\text {a S. Murthy, }}{ }^{\text {b X. Shao, }}{ }^{\text {a D.J. Demetrick, }}{ }^{\mathrm{b}}$ and \\ F.A. van der Hoorna \\ a Department of Medical Biochemistry, Southern Alberta Cancer Research Centre and \\ ${ }^{b}$ Department of Pathology, University of Calgary, Calgary, Alberta (Canada)
}

\begin{abstract}
The product of the spermatid-specific rat SPAG4 gene interacts specifically with the major $27-\mathrm{kDa}$ outer dense fiber protein ODF27 in elongating spermatids. In this study we
\end{abstract}

isolated the human homolog of the spermatid-specific rat SPAG4 gene and mapped it by fluorescence in situ hybridization to chromosome $20 \mathrm{q} 11.2$.
Mammalian sperm tails contain, besides an axoneme, two unique components: outer dense fibers (ODF), which extend along the entire tail, and a fibrous sheath (FS), which initiates at the stack of mitochondria and surrounds the ODF until the end of the sperm tail (Fawcett, 1970; Phillips, 1972). Defects in these structures have been associated with reduced sperm tail motility and human infertility. Early studies indicated that ODF proteins are testis specific and are synthesized in elongating spermatids (Oko and Clermont, 1989). Although the major ODF proteins were isolated several years ago (Olson and Sammons, 1980; Vera et al., 1984; Oko, 1988), until recently only one ODF gene, ODF27, had been cloned by us (van der Hoorn et al., 1990) and others (Burfeind and Hoyer-Fender, 1991; Morales et al., 1994). Thus the molecular tools to establish correlations between genetic defects, abnormal ODF structures, and human male infertility are severely limited. We recently used a yeast two hybrid screening with the leucine zipper region

Supported by grants from the Medical Research Council of Canada (F.A.v.d.H.) and Canadian Breast Cancer Research Initiative (D.J.D.). D.G. was supported by an Alberta Cancer Board Summer Studentship.

Received 9 September 1997; revision accepted 12 March 1998

Request reprints from Dr. F.A. van der Hoorn, Department of Medical Biochemistry, University of Calgary Health Sciences Centre, 3330 Hospital Drive NW,

Calgary, Alberta T2N 4N1 (Canada); telephone: 403-220-3323;

fax: 403-283-8727; e-mail: fvdhoorn@acs.ucalgary.ca. of ODF27 (Shao and van der Hoorn, 1996) as bait to isolate rat testis-specific proteins that can interact with ODF27 (Shao et al., 1997). We demonstrated that one of these novel genes, 111450 , encodes the major $84-\mathrm{kDa}$ ODF protein (Shao et al., 1997). Its human homolog has been localized to 8q22 (Gastmann et al., 1993). Another one of the new genes, SPAG4, also interacts strongly with ODF27 via a leucine zipper and is expressed exclusively in elongating spermatids in a transient fashion: protein synthesis is maximal during maximal ODF27 synthesis and growth of the sperm tail. However, the product of the SPAG4 gene is not incorporated into the mature sperm tail (Shao et al., manuscript submitted for publication). In this study we cloned the human SPAG4 homolog and used it in fluorescence in situ hybridization (FISH) to map SPAG4 to chromosome 20q11.2.

\section{Materials and methods}

Cosmid library and isolation of the human SPAG4 gene

The cosmid library was constructed from an anonymous human placental genomic DNA sample that was partially digested with Sau3A and cloned into SuperCos (Stratagene) per the manufacturer's instructions. The average insert size from several irrelevant clones was 30-35 kb. Approximately $1 \times$ $10^{6}$ genomic clones were screened using a rat SPAG 4 cDNA as probe under high stringency $\left(65^{\circ} \mathrm{C}, 0.1 \times \mathrm{SSC}\right.$, and $\left.0.1 \% \mathrm{SDS}\right)$. Five positive clones were isolated and analyzed by restriction mapping, and selected fragments that hybridized to SPAG4 rat cDNA were sequenced to define exon-intron boundaries. \begin{tabular}{ll}
\hline KARGER & $\begin{array}{l}\text { E-mail karger@karger.ch } \\
\text { Fax }+41613061234\end{array}$
\end{tabular} http://www.karger.com
(C) 1996 S. Karger AG, Basel 0301-0171/98/0811-0065\$15.00/0 
human SPAG4 gene

rat SPAG4 CDNA

human SPAG4 gene rat SPAG4 CDNA

human SPAG4 gene rat SPAG4 CDNA
TTCCAG | GAGCCTCCATCGACCTGCAGAAGACATCCCACGAT CTGTGG | GAGCCICCATCGACCTGGAGAAGACATCCAGTGAC

TACGCAGACAGGAACACTGCCTACTTCTGGAATCGCTTCAGC TACGAGGACCGGAATACTGCCTACTTCTGGAACCGATTAAGC

TTCTGGAACTACGCACGGCCGCCCACGGTTATCCTGGAG| GTGAG TTCTGGAACTACGCCCGCCCACCCTCTGTCATATIGGAG | CCAGA

5' SPLICE SITE

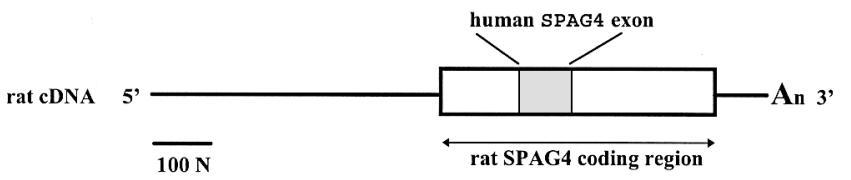

Fig. 1. Nucleotide sequence of a human SPAG4 gene exon. The nucleotide sequence of one exon of the human SPAG4 gene is compared to the corresponding rat SPAG4 cDNA sequence. Indicated are the $5^{\prime}$ and $3^{\prime}$ exonintron boundaries in the human sequence and the relative location of this exon on the rat SPAG4 cDNA.

\section{FISH}

FISH was performed using previously established methods on methotrexate/thymidine-synchronized, phytohemagglutinin-stimulated, normal peripheral blood lymphocytes (Demetrick, 1995). Suppression for $30 \mathrm{~min}$ with a mixture of sonicated human DNA (Sigma) and Cot-1 DNA (GIBCO $\mathrm{BRL}$ ) was required to reduce the background. The stained slides were counterstained with DAPI and actinomycin D (to produce a DA/DAPI banding pattern), mounted in antifade medium, and visualized utilizing a Zeiss Axioplan 2 microscope. Approximately 30 metaphase spreads were examined for probe localization. Images of representative mitoses were captured using a cooled CCD camera (Photometrics PXL 1400). Digital alignment of the images from each fluor was done after registration calibration through a triple bandpass filter (FITC/Texas Red/DAPI) to minimize registration error, utilizing commercial software (Electronic Photography version 1.3; Biological Detection).

\section{Results and discussion}

We isolated several positive clones from a human placental cosmid library using a rat SPAG4 cDNA as probe. All were analyzed by restriction mapping. One of these, called cosmid $8-800$, was further investigated by sequencing of selected fragments in order to confirm (1) the presence of the SPAG4 reading frame and (2) the presence of exon-intron boundaries. Figure 1 shows the location and sequence of the analyzed human exon compared to the rat SPAG4 cDNA, indicating the high degree of homology between rat and human SPAG4 genes and confirming the identity of the genomic cosmid clone.

To identify the chromosomal localization of the SPAG4 gene, a 30-kb cosmid DNA probe was labeled with digoxigenindUTP and hybridized to synchronized human lymphocyte metaphase spreads, as detailed above. These results clearly show localization of the probe to $20 \mathrm{q} 11.2$. At least one specific probe signal was present in more than $90 \%$ of the mitoses examined. Approximately $80 \%$ of the spreads showed labeling of two chromatids of a single chromosome, and more than half of these showed specific labeling of both chromatids of both

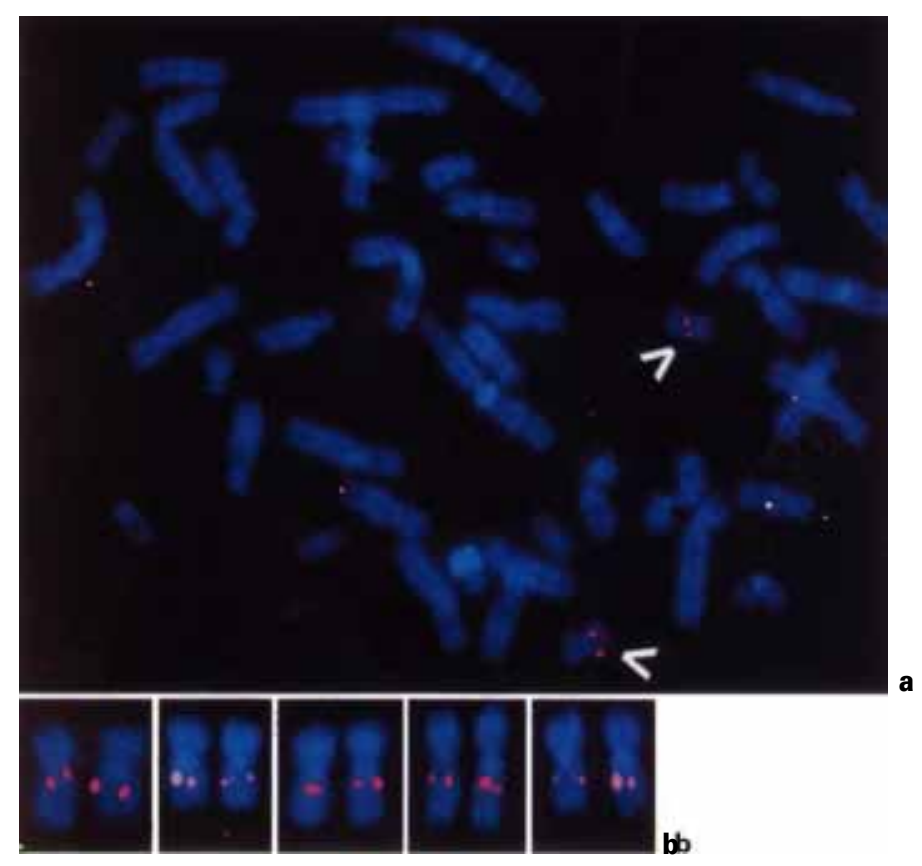

Fig. 2. Localization of gene SPAG4 on human metaphase chromosomes. (a) Metaphase spread with specific dual-chromatid staining of a Cy3-labeled genomic SPAG4 gene probe (red) to 20q11.2 on DA/DAPI-stained (whiteblue) normal human chromosomes. (b) Several enlarged pairs of chromosome 20 from different metaphase cells showing consistent localization of the SPAG4 probe (red) to normal DA/DAPI-stained human chromosomes.

chromosomes (Fig. 2). More than $90 \%$ of these signals were localized to a single band, 20q11.2.

In this region of chromosome 20, 159 cDNA markers have been mapped to date, none of which appears to encode a testisspecific transcript. The ODF27 protein, with which the SPAG4 protein interacts, localizes to human chromosome 8q22 (Gastmann et al., 1993). Thus the ODF27 and SPAG4 genes, which are both exclusively transcribed in male germ cells and whose products interact in a highly specific fashion during spermatogenesis, are not genetically linked. The availability of antisera raised against the ODF27, ODF84, and SPAG4 proteins and the present chromosomal localization studies will allow the analysis of possible correlations between human male infertility syndromes and genetic defects in these major structural components.

\section{Acknowledgements}

We thank Dr. D. Edwards for critical reading of the manuscript. We thank the Faculty of Medicine, University of Calgary, for an Establishment Grant for the FISH equipment. 


\section{References}

Burfeind R, Hoyer-Fender S: Sequence and developmental expression of an mRNA encoding a putative protein of rat sperm outer dense fibers. Devl Biol 148:195-204 (1991).

Demetrick DJ: Fluorescence in situ hybridization and human cell cycle genes, in Pagano M (ed): The Cell Cycle-Materials and Methods, pp 29-45 (Springer Verlag, Berlin/Heidelberg/New York 1995).

Fawcett DW: A comparative view of sperm ultrastructure. Biol Reprod 2(Suppl):90-127 (1970).

Gastmann O, Burfeind P, Gunther E, Hameister H, Szpirer C, Hoyer-Fender S: Sequence, expression, and chromosomal assignment of a human sperm outer dense fiber gene. Mol Reprod Dev 36:407418 (1993).
Morales CR, Oko R, Clermont Y: Molecular cloning and developmental expression of an mRNA encoding the $27 \mathrm{kDa}$ outer dense fiber protein of rat spermatozoa. Mol Reprod Dev 37:229-240 (1994).

Oko R: Comparative analysis of proteins from the fibrous sheath and outer dense fibers of rat spermatozoa. Biol Reprod 39:169-182 (1988).

Oko R. Clermont Y: Light microscopic immunocytochemical study of fibrous sheath and outer dense fiber formation in the rat spermatid. Anat Rec 225:46-55 (1989).

Olson GE, Sammons DW: Structural chemistry of outer dense fibers of rat sperm flagellum. Biol Reprod 22:319-332 (1980).

Phillips DM: Comparative analysis of mammalian sperm motility. J Cell Biol 53:561-573 (1972).
Shao X, van der Hoorn FA: Self-interaction of the major 27-kilodalton outer dense fiber protein is in part mediated by a leucine zipper domain in the rat. Biol Reprod 55:1343-1350 (1996).

Shao X, Tarnasky HA, Schalles U, Oko R, van der Hoorn FA: Interactional cloning of the $84-\mathrm{kDa}$ major outer dense fiber protein ODF84: leucine zippers mediate associations of ODF84 and ODF27. J biol Chem 272:6105-6113 (1997).

van der Hoorn FA, Tarnasky HA, Nordeen SK: A new rat gene RT7 is specifically expressed during spermatogenesis. Dev Biol 142:147-154 (1990).

Vera JC, Brito M, Zuvic T, Burzio LO: Polypeptide composition of rat sperm outer dense fibers. J Biol Chem 259:5970-5977 (1984). 